\title{
Comparative evaluation of roundabout capacities under heterogeneous traffic conditions
}

\author{
Ramu Arroju' ${ }^{1}$ Hari Krishna Gaddam ${ }^{1}$ Lakshmi Devi Vanumu ${ }^{1}$. \\ K. Ramachandra Rao ${ }^{2}$
}

Received: 3 July 2015/Revised: 29 October 2015/ Accepted: 31 October 2015 / Published online: 25 November 2015

(C) The Author(s) 2015. This article is published with open access at Springerlink.com

\begin{abstract}
In heterogeneous traffic conditions, roundabout capacity is described by vehicle and driver characteristics which are different from traffic conditions in homogeneous conditions. In the present study, the capacity of the roundabout is determined using various capacity formulas such as gap acceptance models given by Highway Capacity Manual 2010 (US), German model (2001); empirical regression models given by TRRL (UK) and weaving models given by IRC: 65-1976 (India). In addition, microscopic simulation model like VISSIM (PTV Germany) is also used to derive capacity values. Unlike the other capacity estimation models, VISSIM is helpful in estimating capacity values using geometric and driver characteristics and it can also simulate heterogeneous traffic condition accurately. Capacity is estimated after calibrating the simulation model (VISSIM) developed for the roundabout. This is achieved by incorporating different vehicle classes to represent the heterogeneous traffic environment, driver gap acceptance, and lane change
\end{abstract}

K. Ramachandra Rao

rrkalaga@civil.iitd.ac.in

Ramu Arroju

ramu.arroju@gmail.com

Hari Krishna Gaddam

harikrishnagaddam@gmail.com

Lakshmi Devi Vanumu

lakshmidevivanumu@gmail.com

1 Department of Civil Engineering, IIT Delhi, Hauz Khas, New Delhi, India

2 Department of Civil Engineering and Transportation Research and Injury Prevention Programme (TRIPP), IIT Delhi, Hauz Khas, New Delhi, India parameters. All the required inputs were extracted from the video using semi-automatic data collection methods. Data are used for the estimation of capacity values from different methods mentioned above and for the calibration and validation of simulation model. The capacity values estimated form various formulas except German model are distinctly different from the field values and they are either overestimating or underestimating. Analysis of these observations reveals that the capacity values from VISSIM and German models are nearly matching with the field capacity.

Keywords Roundabout · Capacity · VISSIM ·

Simulation $\cdot$ Heterogeneous

\section{Introduction}

Roundabouts have many advantages compared to other regular signalized intersections. The main advantages are traffic safety, operational performance, environmental factors, pedestrian safety, and aesthetics [1]. Signalized intersection has 32 conflict points whereas roundabout with one circulating lane and one entry lane has 8 traffic conflict points. But the number of conflicts increases to 16 in the case of roundabout with two circulating and two entry lanes. Conflict points at signalized intersection and roundabout with one circulating and one entry lane are depicted in Figs. 1 and 2, respectively. The reduced number of conflict points at a roundabout indicates the reduction of crash propensity. The increased use of roundabout as a traffic facility needs an overall assessment on potential accident rates [2]. For the safe movement of the vehicles, it is essential to understand the operational performance of the roundabout. Capacity is one such parameter which 


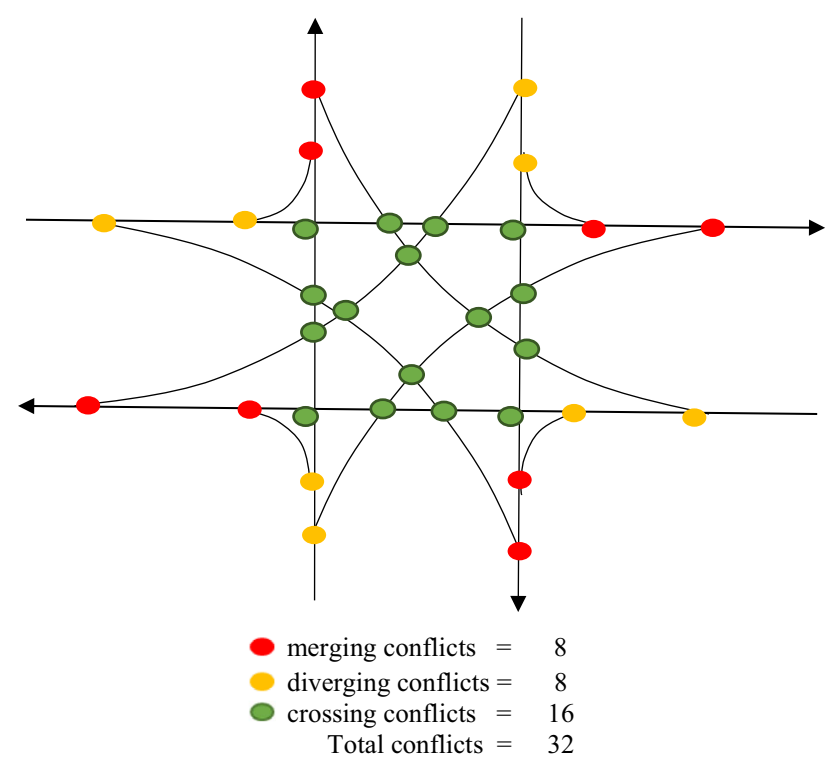

Fig. 1 Conflict points at signalized intersections

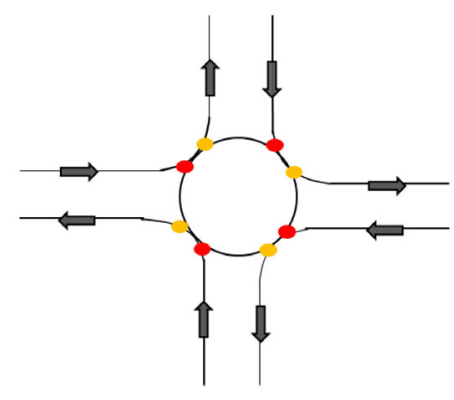

merging conflicts $=4$

diverging conflicts $=4$

crossing conflicts $=0$

Total conflicts $=8$

Fig. 2 Conflict points at a single-lane Roundabout

explains the operational performance, traffic scenario, and level of service.

In contrast to traffic flow condition in developed countries, Indian traffic condition is totally different. Apart from the different driver classes, vehicles with various performance and dimensional characteristics (especially traffic is predominantly occupied by small sized vehicles such as motor two wheelers and auto rickshaws), non-lane discipline, and creeping behavior are characterized a totally complex traffic environment. It requires special attention in modeling traffic flow behavior. Several capacity formulas under steady-state conditions are developed for various countries such as Highway Capacity Manual (HCM) method for US [3], TRRL method for UK [3], German method [3], and IRC method for India [4]. However, these are very limited in terms of being able to reproduce the actual traffic conditions prevalent and also they do not have many calibration parameters to improve the estimates. VISSIM microscopic simulation helps in addressing this aspect. Besides, it has several calibration parameters which can also help improve the accuracy of the capacity estimates. The heterogeneous traffic can be introduced by importing various vehicle 3D models which are not in VISSIM by default like Auto, etc. It can incorporate both geometry of the roundabout and driver gap acceptance behavior and hence is the most accurate to estimate capacity compared to all the methods available. So, in this study, the first objective is to calibrate and validate the VISSIM model for heterogeneous traffic situation. Few Methods have been developed to estimate empirical capacity values using different approaches [5, 6], and comparative analysis of the several models can also be done using flows and delays [7]. As a second objective, in the present study, we adopted a new approach to estimate empirical capacity values to compare the performance of various methods in estimating capacity values.

The remaining portion of the paper is structured as follows. The second section explains about capacity estimation methods. The third section tells about the methodology adopted for this study, data collection procedure, calibration, and validation. The fourth section illustrates the capacity values estimated from various methods and comparison of capacity values. The fifth is about the conclusions.

\section{Capacity estimation}

Capacity of an entry of the roundabout is described as the smallest value of the leg flow that causes the permanent formation of queue up to enter [3]. Total capacity of the roundabout is the sum of all the capacities at the entries under saturated conditions. There are various studies on capacity estimation of roundabouts that have been done all over the world in the past. Kimber proposed the detailed capacity model of a roundabout in the UK, which is a linear regression model between the entry capacity and conflicting flow rate [3]. IRC: 65-1976 established a method for estimating practical capacity of the weaving section of a rotary, which is mainly based on the geometry of the Rotary [4]. Bovy et al., developed a linear model for capacity estimation based on studies of roundabouts in Switzerland [3]. Troutbeck developed analytical equations based on driver gap acceptance characteristics at Australian Road Research Board [9]. The HCM 2000 is one of the popular models of roundabout capacity based on gap acceptance. In the 2010 version of the Highway Capacity Manual, a detailed procedure was developed for estimating the capacity and level of service of roundabouts in the United States. These capacity models combine a gap acceptance model along with exponential regression and 
can be calibrated by estimating the critical headway and follow-up headway [10]. Chandra and Rastogi compared capacity values that are derived from different methods with their proposed method where they considered entry flow and circulating flow for estimating capacity values [11].

VISSIM is a microscopic, time-step, and behavior-based simulation model developed to analyze different types of classified roadways and public transportation operations. It has excellent graphical capabilities, and has an ability to realistically model traffic operations at roundabouts through user-defined parameters [12]. Simulation in VISSIM focuses on random distributions of driver behavioral attributes such as aggressiveness and gap acceptance, and other parameters such as vehicle arrivals, vehicle speeds, vehicle type, and others [13]. The most essential prerequisite to create a VISSIM roundabout model is to calibrate the model by adjusting VISSIM parameters and hence calibration part must be crucial [14]. The VISSIM software actually contains a large number of simulation parameters that can affect the simulation results (network, vehicle, and driver characteristics). The calibration process should focus mainly on the parameters that have significant effect on the results [15]. VISSIM simulates longitudinal and lateral vehicle movements in traffic flows by a psycho-physical car following model based on Wiedemann's model [16].

Various methods used for capacity estimation of roundabouts are discussed here.

\subsection{HCM 2010 method}

The HCM 2010 method proposes an exponential function based on gap acceptance theory for evaluating the entry capacity of single-lane and two-lane roundabouts.

The roundabout capacity equation is given as follows:

$C=A \cdot e^{\left(-B \cdot v_{\mathrm{c}}\right)}$,

where $C$ is lane capacity $(\mathrm{veh} / \mathrm{h})$, and $v_{\mathrm{c}}$ is conflicting or circulating flow rate $(\mathrm{veh} / \mathrm{h})$.

The parameters $A$ and $B$ of the above equation are calculated with the help of critical headway and follow-up headway as follows:

$A=\frac{3,600}{t_{\mathrm{f}}}$,

$B=\frac{t_{\mathrm{c}}-\left(\frac{t_{\mathrm{f}}}{2}\right)}{3,600}$

where $t_{\mathrm{c}}$ denotes critical headway, and $t_{\mathrm{f}}$ is follow-up headway. As per HCM 2010, the default parameters for $A$ and $B$ are as follows: $A=1,130, B=0.0010$ for singlelane entry and single-lane circulating stream (corresponding to $t_{\mathrm{f}}=3.19 \mathrm{~s}$ and $t_{\mathrm{c}}=5.19 \mathrm{~s}$ ) and for a two-lane entry and multilane circulating stream $A=1,130, B=0.0007$ for right lane (corresponding to $t_{\mathrm{f}}=3.19 \mathrm{~s}$ and $\left.t_{\mathrm{c}}=4.11 \mathrm{~s}\right)$ or $A=1,130, B=0.00075$ for left lane (corresponding to $t_{\mathrm{f}}=3.19 \mathrm{~s}$ and $t_{\mathrm{c}}=4.29 \mathrm{~s}$ ).

\subsection{TRRL (UK) linear regression model}

Kimber developed a set of equations for urban single-lane and two-lane roundabouts for estimating entry capacities $\left(Q_{\mathrm{e}}\right)$ [3] . The set of equations is based on roundabout geometric parameters, and Eqs. 4-10 represent those equations.

$Q_{\mathrm{e}}= \begin{cases}K\left(F-f_{\mathrm{c}} \cdot Q_{\mathrm{c}}\right), & f_{\mathrm{c}} \cdot Q_{\mathrm{c}} \leq F \\ 0, & f_{\mathrm{c}} \cdot Q_{\mathrm{c}}>F\end{cases}$

where

$K=1-0.00347(\varphi-30)-0.978\left(\frac{1}{r}-0.05\right)$,

$F=303 x_{2}$,

$f_{\mathrm{c}}=0.210 t_{\mathrm{D}}\left(1+0.2 x_{2}\right)$,

$t_{\mathrm{D}}=1+\frac{0.5}{1+\exp \left(\frac{D-60}{10}\right)}$,

$x_{2}=v+\frac{e-v}{1+2 S}$,

$S=\frac{1.6(e-v)}{l^{\prime}}$,

where $Q_{\mathrm{e}}$, is the entry capacity, veh $/ \mathrm{h}, Q_{\mathrm{c}}$ is the circulating flow, veh/h, $e$ is the entry width, $\mathrm{m}, v$ is the approach half width, $\mathrm{m}, l^{\prime}$ is the effective flare length, $\mathrm{m}, S$ is the sharpness of flare, $\mathrm{m} / \mathrm{m}, D$ is the inscribed circle diameter, $\mathrm{m}, \varphi$ is the entry angle, ${ }^{\circ}$, and $r$ is the entry radius, $\mathrm{m}$.

\subsection{The Indian Roads Congress Method (IRC 65-1976)}

In this method, the practical capacity of a roundabout is considered as similar to that of the capacity of the weaving section of the roundabout which is as follows.

$Q_{\mathrm{p}}=\frac{280 w\left(1+\frac{e}{w}\right)\left(1-\frac{p}{3}\right)}{1+\frac{w}{l}}$,

where $Q_{\mathrm{p}}$ is the practical capacity of the weaving section in $\mathrm{pcu} / \mathrm{h}, w$ is the width of weaving section in meters (within the range of $6-18 \mathrm{~m}), w=\frac{e_{1}+e_{2}}{2}+3.5, e$ is the average entry width in meters $\left(e=\frac{e_{1}+e_{2}}{2}\right), e / w$ to be within the range of $0.4-1, l$ is the length in meters of the weaving section between the ends of the channelizing islands ( $w / l$ to be within the range of $0.12-0.4), p$ is the proportion of weaving traffic, i.e., ratio of sum of crossing streams to the 
total traffic on the weaving section, given by $p=\frac{b+c}{a+b+c+d}$, the range of $p$ being $0.4-1$.

The parameters $a, b, c, d$ for a weaving section between two legs of a roundabout are given in Table 1 , where $W_{i j}$ represents weaving section between leg $i$ and $\operatorname{leg} j$ and $T_{i j}$ represents vehicle turning movement counts from leg $i$ to leg $j$. Legs are numbered in clock wise direction as shown in Fig. 4.

\subsection{German method}

Brilon and $\mathrm{Wu}$ proposed a formula for capacity of a roundabout in 1997 based on the idea from Tanner [17]. For a double-lane circle and double-lane entries, the capacity is given as follows.

$C=3,600 \cdot \frac{n_{\mathrm{e}}}{T_{\mathrm{f}}} \cdot \exp \left[-\frac{Q_{\mathrm{c}}}{3,600} \cdot\left(T_{\mathrm{c}}-\frac{T_{\mathrm{f}}}{2}\right)\right]$,

where $C$ is the capacity (vph), $Q_{\mathrm{c}}$ is the circulating flow in front of entry (vph), $n_{\mathrm{e}}$ is the parameter connected to number of entry lanes, which equals to 1 for single-lane entries and 1.4 for double-lane entries, $T_{\mathrm{c}}$ is the critical headway (s), and $T_{\mathrm{f}}$ is the follow-up time (s).

\section{Methodology}

The VISSIM input parameters such as volume counts, average speed, or speed profile along the roundabout and other geometric details which are obtained from data collection are entered in the VISSIM software. Then we need to calibrate the model using trail-and-error approach. If the results obtained from the simulation and the field results are nearly same, which means the error (MAPE) observed is the minimum, then the model is said to be representing the actual traffic. Methodology for capacity estimation using various methods is shown in Fig. 3.

\subsection{Data collection}

Two roundabouts are selected for this study, which are located in Chanakyapuri area of New Delhi. The first one is Satya Marg-Vinay Marg roundabout and the second one is Satya Marg-Niti Marg roundabout. The study locations are depicted in Fig. 4. The roundabout legs north bound (NB),

Table 1 Parameters for weaving traffic

\begin{tabular}{lllll}
\hline Weaving section & $a$ & $b$ & $c$ & $d$ \\
\hline$W_{12}$ & $T_{12}$ & $T_{13}+T_{14}$ & $T_{42}+T_{32}$ & $T_{43}$ \\
$W_{23}$ & $T_{23}$ & $T_{24}+T_{21}$ & $T_{13}+T_{43}$ & $T_{14}$ \\
$W_{34}$ & $T_{34}$ & $T_{31}+T_{32}$ & $T_{14}+T_{24}$ & $T_{21}$ \\
$W_{41}$ & $T_{41}$ & $T_{42}+T_{43}$ & $T_{21}+T_{31}$ & $T_{32}$ \\
\hline
\end{tabular}

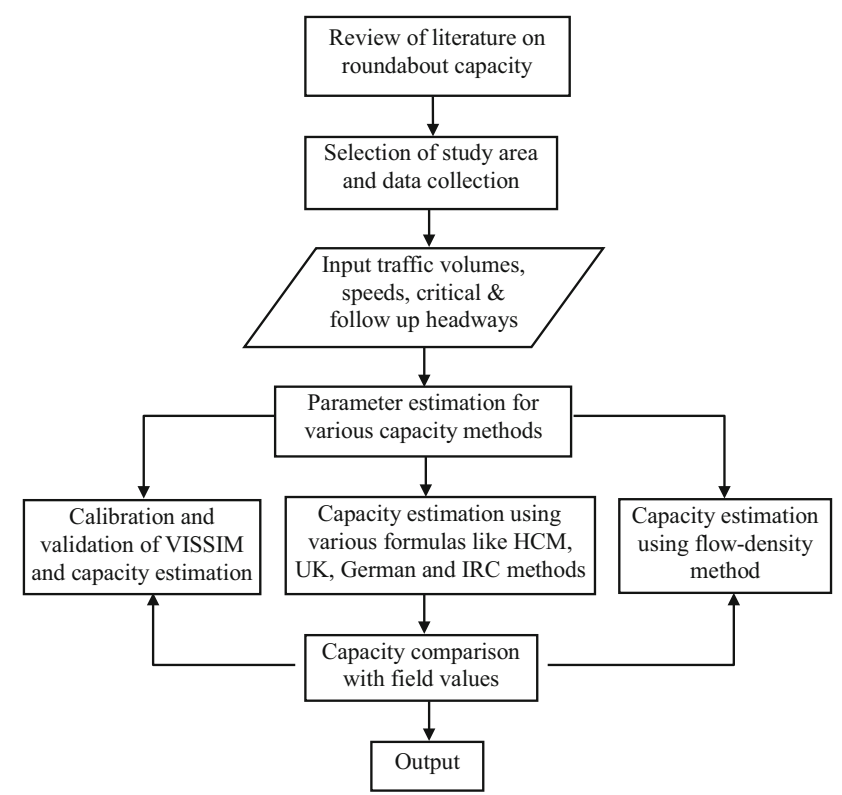

Fig. 3 Methodology of capacity estimation using various methods

east bound (EB), south bound (SB), and west bound (WB) are numbered as legs $1,2,3$, and 4 in clockwise direction and similar nomenclature is used throughout the paper. The two roundabouts have different geometric configurations where the diameter of roundabout $2(55.36 \mathrm{~m})$ is larger than roundabout $1(48.31 \mathrm{~m})$. Roundabout 1 has 3-lane entry $(10.5 \mathrm{~m})$ in north bound (leg 1) and south bound (leg 3) directions and 2-lane entry $(7.0 \mathrm{~m})$ in east bound $(\operatorname{leg} 2)$ and west bound (leg 4) directions. But roundabout 2 consists of 2 lane entry in all directions. Both roundabouts consist of 2-lane circulating stream with the width of $7.5 \mathrm{~m}$. A pilot survey is conducted at these roundabouts prior to main data collection to come across various problems that may be encountered during data collection and also to have a rough estimate of the flow at these roundabouts.

Manual method of vehicle count is adopted as the turning movements of all vehicles are difficult to extract from a video. In total, 13 trained enumerators were used for this purpose of which 4 persons are assigned to count entry flows at 4 legs, 4 persons for exit flows at 4 legs, and 4 more persons are asked to count the left turning vehicles.

In addition, one more person counted the vehicles in the weaving section between legs 1 and 2. From these data, all the turning movements are estimated using Gaussian elimination method and the circulating flows in front of the splitter island of all the legs are calculated using the conservative equations $[18,19]$. Traffic volume data were collected in three different sessions, i.e., morning, afternoon, and evening. By using total traffic volume, capacity values of each leg of the roundabout were estimated using fundamental diagrams and capacity equations such as HCM method, TRRL (UK) method, German method, and IRC method. 


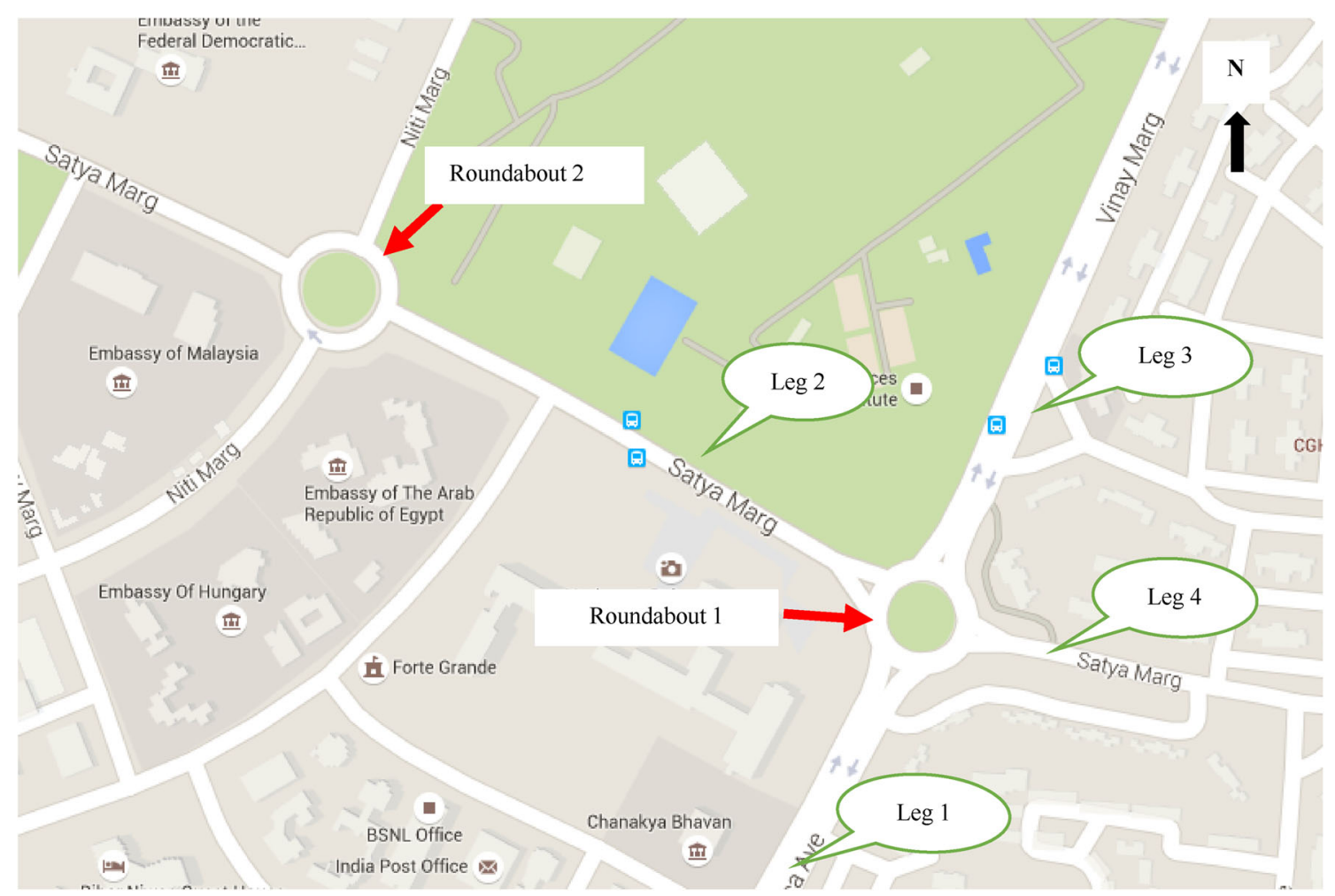

Fig. 4 Location of two roundabouts at Chanakyapuri in New Delhi (India) (Source: Google Maps)

Table 2 Vehicle dimensions and dynamical characteristics

\begin{tabular}{|c|c|c|c|c|c|c|c|c|c|c|}
\hline \multirow[t]{2}{*}{ Vehicle type } & \multirow[t]{2}{*}{ Length (m) } & \multirow[t]{2}{*}{ Width (m) } & \multicolumn{4}{|c|}{ Percentile speeds $(\mathrm{km} / \mathrm{h})$} & \multicolumn{2}{|c|}{ Acceleration $\left(\mathrm{m} / \mathrm{s}^{2}\right)$} & \multicolumn{2}{|c|}{ Deceleration $\left(\mathrm{m} / \mathrm{s}^{2}\right)$} \\
\hline & & & 15 th & 50th & 85th & 98th & $\operatorname{Max}$ & Desired & $\operatorname{Max}$ & Desired \\
\hline Car & 4.2 & 2 & 33 & 42 & 51 & 60 & 1.7 & 1.2 & 1.2 & 1 \\
\hline TW & 2 & 0.84 & 27 & 35 & 43 & 52 & 2.5 & 1.7 & 1.7 & 1.2 \\
\hline Auto & 2.36 & 1.17 & 22 & 31 & 38 & 43 & 1.2 & 0.9 & 1.1 & 0.8 \\
\hline Bus & 11.54 & 2.69 & 19 & 30 & 36 & 42 & 1.2 & 1.0 & 1.0 & 0.9 \\
\hline Truck & 10.21 & 2.5 & 21 & 32 & 43 & 45 & 1.0 & 0.8 & 1.0 & 0.8 \\
\hline
\end{tabular}

Speed plays a crucial role in implementing VISSIM model for heterogeneous traffic and also helps in calibration and validation. Spot speed values of different categories of vehicles are collected using speed guns at entry points, weaving points, and at some distance away from the roundabout. Percentile speeds from speed distribution curves are extracted for all categories of vehicles as input in VISSIM. Vehicle dimensions and percentile speeds adopted for VISSIM are shown in Table 2. Space mean speed values are estimated using time mean speed values and used in plotting fundamental diagrams to find empirical capacity values. Simultaneously during manual count, video cameras are also arranged at all the legs to capture the gap acceptance and following behavior of the drivers. The critical headway and follow-up headways are extracted from these videos. Raffs method is used for critical headway estimation which is the intersection point of an increasing and a decreasing cumulative distribution curves of accepting and rejecting gaps. Weighted average for the critical headway and follow-up headways of each leg are determined and used as inputs for the HCM and VISSIM models to estimate capacity. Effect of physical dimensions of the vehicles on behavior of traffic stream is evident especially in the presence of big size vehicles (acts as a moving bottlenecks), and smaller size vehicles like two wheelers (high maneuverability) have profound influence on the capacity of the facility. Vehicle dimensions and percentile speeds adopted for VISSIM are shown in Table 2. Vehicle dimensions given in Table 2 are used as standard dimensions in VISSIM. Percentile speed values 


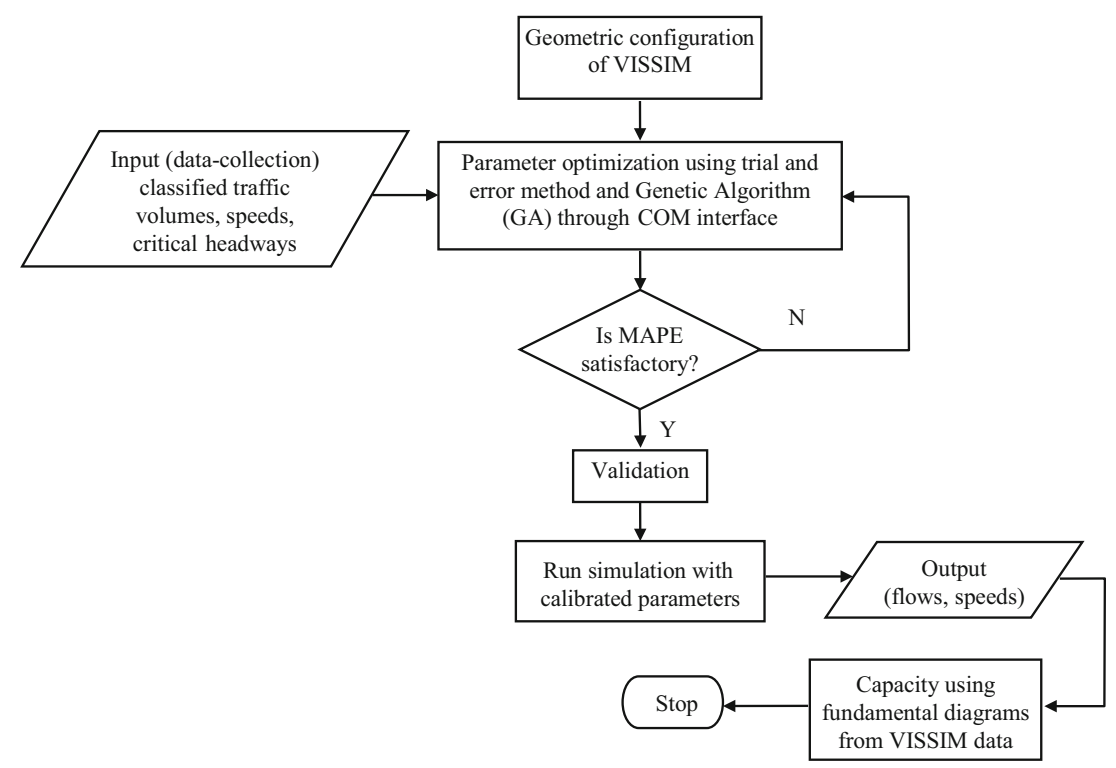

Fig. 5 Calibration procedure for VISSIM for roundabout capacity estimation

presented in Table 2 are observed at roundabout 1 and similar analysis is also done for roundabout 2 .

\subsection{Calibration}

VISSIM software simulates longitudinal and lateral vehicle movements in traffic flows by a psycho-physical car-following model proposed by Wiedemann in 1974. According to this model, a vehicle changes its acceleration only when the distance in front falls below a minimum value. Calibration procedure for optimizing VISSIM parameter values is given in Fig. 5.

VISSIM parameters are calibrated using two different approaches namely trail-and-error approach and genetic algorithm (GA). MATLAB ${ }^{\circledR}$-based Component Object Model (COM) interface is developed to control VISSIM parameters. Single-objective GA function is used in optimization. The results of this study are mixed and need further investigation (Appendix). In trial and error method, initially the model is run with default parameters. Mean absolute percentage error (MAPE) value obtained between field data and VISSIM simulation data for entry flow is used to check whether the model is close enough to real world scenario. If the MAPE value obtained is much higher, then the default parameters have to be changed in systematic manner such that the error keeps on reducing. In this process, three parameters of Wiedemann 74 car following model, i.e., average stand still distance ( $a x)$, additive part of safety distance (bx_add), and multiplicative part of safety distance (bx_mult), are calibrated. Initially, $a x$ is varied fixing the other two parameters and simulations are run, and the $a x$ value whose corresponding MAPE
Table 3 Calibration errors for roundabout 1

\begin{tabular}{llllllc}
\hline Trial no. & $a x$ & $b x \_$add & $b x \_$mult & $\begin{array}{l}\text { Min error } \\
(\%)\end{array}$ & $\begin{array}{l}\text { Max } \\
\text { error }(\%)\end{array}$ & MAPE \\
\hline $\begin{array}{c}\text { Default } \\
\text { trial }\end{array}$ & 2 & 2 & 3 & 9.76 & 30.05 & 21.78 \\
1 & 2.5 & 2 & 3 & 11.42 & 34.82 & 22.9 \\
2 & 3 & 2 & 3 & 10.3 & 33 & 22.59 \\
3 & 3.5 & 2 & 3 & 11.44 & 31.86 & 21.28 \\
4 & 4 & 2 & 3 & 16.36 & 35.14 & 23.96 \\
5 & 3.5 & 2.5 & 3 & 10.67 & 31.69 & 17.94 \\
6 & 3.5 & 3 & 3 & 9.88 & 28.61 & 16.06 \\
7 & 3.5 & 3.5 & 3 & 9.02 & 20.85 & 12.62 \\
8 & 3.5 & 4 & 3 & 8.17 & 14.45 & 9.81 \\
9 & 3.5 & 4 & 3.5 & 8.4 & 15.58 & 13.15 \\
10 & 3.5 & 4 & 4 & 9.1 & 15.24 & 12.12 \\
11 & 3.5 & 4 & 4.5 & 13.39 & 21.8 & 18.9 \\
12 & 3.5 & 4 & 5 & 10.52 & 19.88 & 17.52 \\
13 & 3.5 & 4 & 5.5 & 12.06 & 23.42 & 18.47 \\
14 & 3.5 & 4 & 6 & 11.98 & 20.86 & 17.19 \\
\hline
\end{tabular}

value is least is selected. Now, fixing this $a x$ value and $b x \_$mult values, the values of $b x \_$add parameter are changed and simulations are run. In this way, each parameter is changed systematically and the MAPE values between the field observed values and the simulated values are compared, and finally, those parameters with least MAPE value are considered as calibrated values.

Several runs are carried out to find suitable parameters. The errors for four legs of the roundabout are found, and the minimum, maximum, and mean errors (MAPE) are 
tabulated. Sample trails are mentioned in Tables 3 and 4 for roundabout 1 and 2, respectively, and final calibration values are shown in Table 5.

Table 4 Calibration errors for roundabout 2

\begin{tabular}{llllclc}
\hline Trial no. & $a x$ & $b x \_$add & $b x \_$mult & $\begin{array}{l}\text { Min error } \\
(\%)\end{array}$ & $\begin{array}{l}\text { Max } \\
\text { error }(\%)\end{array}$ & MAPE \\
\hline $\begin{array}{l}\text { Default } \\
\text { trial }\end{array}$ & 2 & 2 & 3 & 9.24 & 20.11 & 15.03 \\
1 & 2.5 & 2 & 3 & 9.83 & 17.58 & 15.02 \\
2 & 3 & 2 & 3 & 9.9 & 17.57 & 14.92 \\
3 & 3.5 & 2 & 3 & 8.83 & 22.04 & 15.51 \\
4 & 4 & 2 & 3 & 8.46 & 24.89 & 15.04 \\
5 & 3 & 2.5 & 3 & 9.66 & 16.47 & 13.68 \\
6 & 3 & 3 & 3 & 8.17 & 23.15 & 15.17 \\
7 & 3 & 3.5 & 3 & 10.91 & 27.72 & 16.74 \\
8 & 3 & 4 & 3 & 10.72 & 29.31 & 17.84 \\
9 & 3 & 2.5 & 3.5 & 8.78 & 24.64 & 16.01 \\
10 & 3 & 2.5 & 4 & 10.66 & 17.5 & 13.7 \\
11 & 3 & 2.5 & 4.5 & 9.11 & 10.68 & 9.95 \\
12 & 3 & 2.5 & 5 & 9.67 & 29.5 & 16.9 \\
13 & 3 & 2.5 & 5.5 & 12.6 & 32.11 & 19.59 \\
14 & 3 & 2.5 & 6 & 10.19 & 31.18 & 18.41 \\
\hline
\end{tabular}

Table 5 Calibrated parameters

\begin{tabular}{llll}
\hline Description & $a x$ & $b x \_$add & $b x \_$mult \\
\hline Default values & 2 & 2 & 3 \\
Calibrated values_Roundabout 1 & 3.5 & 4 & 3 \\
Calibrated values_Roundabout 2 & 3 & 2.5 & 4.5 \\
\hline
\end{tabular}

\subsection{Validation}

For validation purpose, speeds at the weaving section between leg 1 and leg 2 of both roundabouts are collected during data collection to compare these values with the weaving speeds obtained from VISSIM. The MAPE values between speeds obtained from VISSIM and field observed speeds are found as 12.35 for roundabout 1 and 13.13 for roundabout 2 . The calculation results are given in Table 6 .

\section{Results and analysis}

\subsection{Critical headway estimation}

The critical headways are calculated using Raff's method, i.e., using graphical representation of cumulative distribution functions of accepted gaps and rejected gaps [20]. The sample figures of critical gap estimation for cars and two

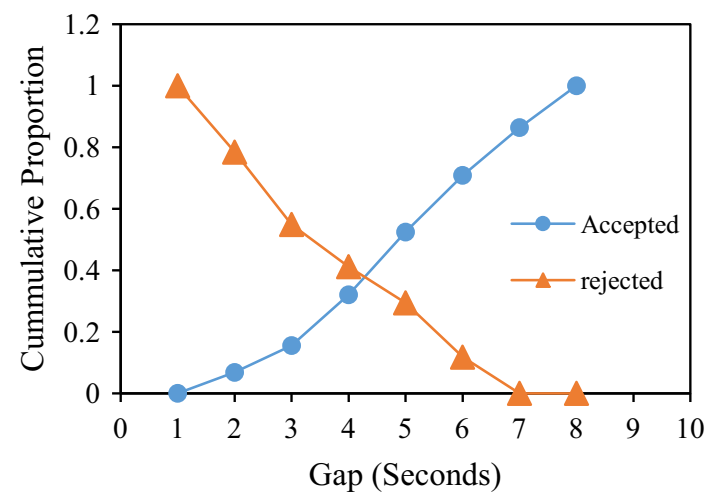

Fig. 6 Critical Head way for $R_{1} / L_{1} / \mathrm{Car}$

Table 6 Validation of roundabout 1 and roundabout 2 using weaving speeds

\begin{tabular}{|c|c|c|c|c|c|c|c|c|}
\hline \multirow{2}{*}{$\begin{array}{l}\text { Time } \\
(\min )\end{array}$} & \multicolumn{4}{|l|}{ Roundabout 1} & \multicolumn{4}{|l|}{ Roundabout 2} \\
\hline & $\begin{array}{l}\text { Weaving speeds from } \\
\text { VISSIM }\end{array}$ & $\begin{array}{l}\text { Observed } \\
\text { weaving speeds }\end{array}$ & $\begin{array}{l}\text { Error } \\
(\%)\end{array}$ & $\begin{array}{l}\text { Absolute } \\
\text { error }\end{array}$ & $\begin{array}{l}\text { Weaving speeds from } \\
\text { VISSIM }\end{array}$ & $\begin{array}{l}\text { Observed } \\
\text { weaving speeds }\end{array}$ & $\begin{array}{l}\text { Error } \\
(\%)\end{array}$ & $\begin{array}{l}\text { Absolute } \\
\text { error }\end{array}$ \\
\hline $0-5$ & 20.00 & 23.46 & -14.73 & 14.73 & 18.77 & 19.18 & -2.16 & 2.16 \\
\hline $5-10$ & 19.59 & 18.35 & 6.78 & 6.78 & 16.92 & 21.37 & -20.84 & 20.84 \\
\hline $10-15$ & 15.78 & 19.69 & -19.85 & 19.85 & 14.29 & 22.81 & -37.35 & 37.35 \\
\hline $15-20$ & 12.99 & 15.65 & -16.97 & 16.97 & 14.02 & 15.98 & -12.29 & 12.29 \\
\hline $20-25$ & 20.48 & 19.38 & 5.67 & 5.67 & 14.27 & 17.42 & -18.07 & 18.07 \\
\hline $25-30$ & 14.20 & 13.70 & 3.68 & 3.68 & 16.67 & 15.30 & 8.97 & 8.97 \\
\hline $30-35$ & 20.30 & 17.31 & 17.27 & 17.27 & 18.82 & 19.19 & -1.94 & 1.94 \\
\hline $35-40$ & 16.43 & 17.33 & -5.21 & 5.21 & 16.85 & 21.87 & -22.94 & 22.94 \\
\hline $40-45$ & 19.25 & 23.39 & -17.69 & 17.69 & 16.29 & 17.21 & -5.34 & 5.34 \\
\hline $45-50$ & 13.73 & 14.91 & -7.92 & 7.92 & 15.67 & 16.32 & -3.98 & 3.98 \\
\hline $50-55$ & 14.11 & 19.23 & -26.60 & 26.60 & 16.11 & 17.38 & -7.32 & 7.32 \\
\hline $55-60$ & 18.00 & 19.11 & -5.79 & 5.79 & 16.74 & 14.39 & 16.34 & 16.34 \\
\hline MAPE & & & & 12.34 & MAPE & & & 13.12 \\
\hline
\end{tabular}




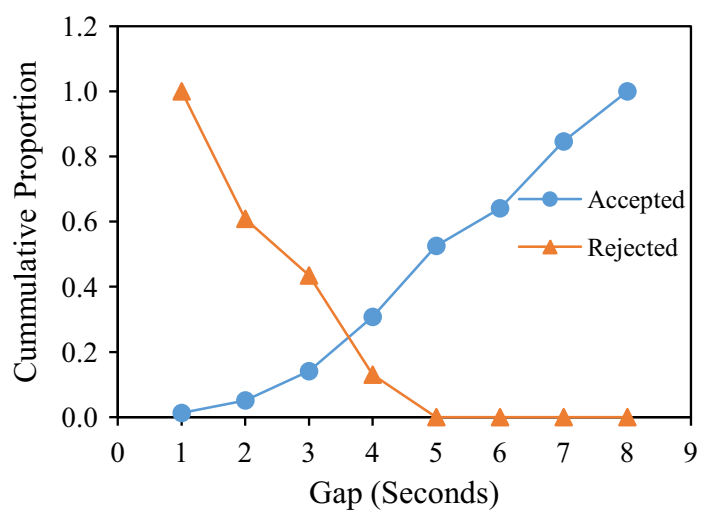

Fig. 7 Critical Head way for $R_{1} / L_{1} / \mathrm{TW}$

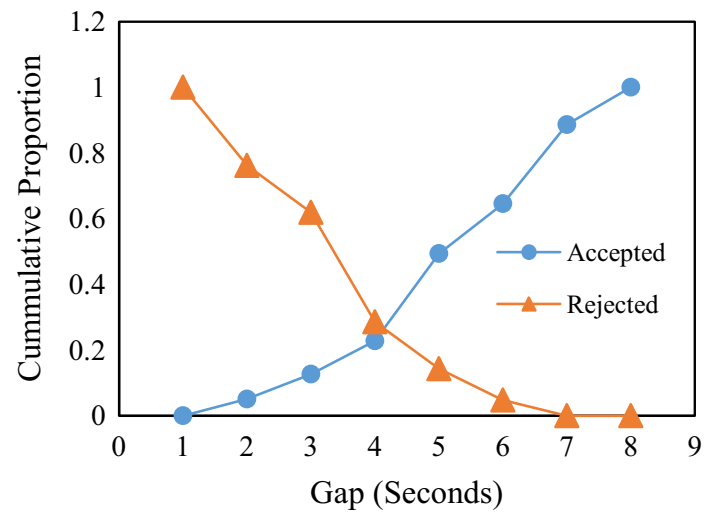

Fig. 8 Critical Head way for $R_{2} / L_{1} / \mathrm{Car}$

wheelers for roundabout 1 and roundabout 2 are shown in Figs. 6, 7, 8, 9. Some sample graphs are as follows. The $R_{i} /$ $L_{j} /$ Mode means roundabout $i /$ Leg $j /$ vehicle Type. The summary of the critical headways obtained for all the vehicles at different legs is given in Tables 7 and 8. Outcome of these results is used in gap acceptance models like HCM 2010 and German Models. The same outcome helps in formulating VISSIM simulation model.

\subsection{Follow-up headway}

The follow-up headway was calculated based on various combinations of leader and follower vehicles among the vehicle types under consideration. A sample table of followup headway calculations for car following other vehicles at leg 1 roundabout 1 is given in Table 9. Similar calculations are done for all other legs for both the roundabouts.

The summary of the follow-up headway values for roundabout 1 is given in Tables 10 and 11. As the number of trucks and buses is very low, the samples from all the legs of both roundabouts are merged and these headway values are used as common for all the legs. The weighted average based on the proportions of various vehicle types is used as follow-up headway for each leg. Similar

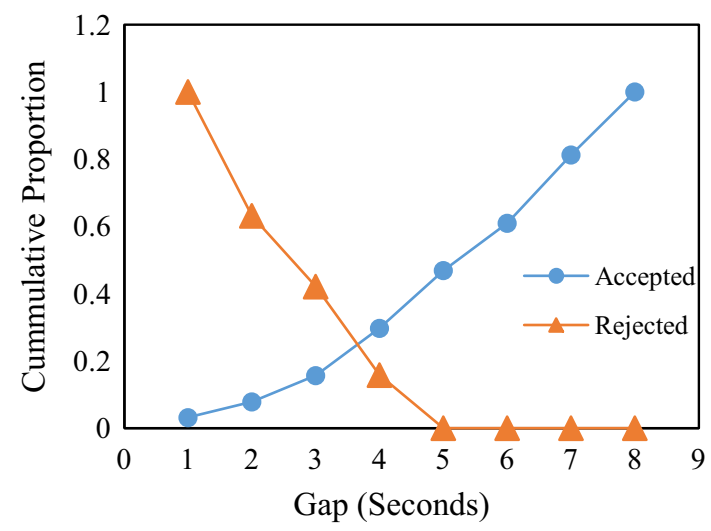

Fig. 9 Critical Head way for $R_{2} / L_{1} / \mathrm{TW}$

Table 7 Critical headways for roundabout 1

\begin{tabular}{lllll}
\hline Mode & Leg 1 (s) & Leg 2 (s) & Leg 3 (s) & Leg 4 (s) \\
\hline Car & 4.2 & 4.3 & 4.5 & 4.3 \\
TW & 3.7 & 3.6 & 3.8 & 3.7 \\
Auto & 4 & 3.7 & 3.9 & 3.9 \\
Bus & 5.69 & 4.5 & 5.05 & 5.1 \\
Truck & 5.02 & 5.14 & 5.81 & 5.3 \\
Weighted average & 4.10 & 4.06 & 4.28 & 4.15 \\
\hline
\end{tabular}

Table 8 Critical headways for roundabout 2

\begin{tabular}{lllll}
\hline Mode & Leg 1 (s) & Leg 2 (s) & Leg 3 (s) & Leg 4 (s) \\
\hline Car & 4.1 & 4.5 & 4 & 4.2 \\
TW & 3.7 & 4 & 3.5 & 3.7 \\
Auto & 3.7 & 3.8 & 4 & 3.8 \\
Bus & 4.45 & 4.33 & 4.57 & 4.5 \\
Truck & 4.92 & 5.74 & 4.78 & 5.1 \\
Weighted average & 3.97 & 4.31 & 3.90 & 4.06 \\
\hline
\end{tabular}

calculations were done for roundabout 2 also. Outcome of these results are helpful in determining capacity values using HCM 2010 and German model.

The capacity values using various methods are calculated. The tables of capacity calculations of roundabouts 1 and 2 are shown below.

\subsection{HCM 2010 method}

Capacity values estimated for all the legs in roundabouts 1 and 2 using HCM method are given in Tables 12 and 13.

\subsection{TRRL (UK) linear regression method}

Capacity values estimated for all the legs in roundabouts 1 and 2 using TRRL (UK) method are given in Tables 14 and 15 . 
Table 9 Sample follow-up headway calculation for roundabout 1 leg 1

\begin{tabular}{|c|c|c|c|c|c|}
\hline \multirow[t]{3}{*}{ Follower } & \multicolumn{5}{|l|}{$R_{1} / L_{1}$} \\
\hline & \multicolumn{5}{|c|}{ Leader (follow-up headway) } \\
\hline & Car (s) & TW (s) & Auto (s) & Bus (s) & Truck (s) \\
\hline \multirow[t]{19}{*}{ Car } & 1.29 & 2.49 & 3.12 & 6.65 & 3.03 \\
\hline & 3.24 & 1.65 & 2.74 & 2.82 & \\
\hline & 10.09 & 3.53 & 2.63 & 3.34 & \\
\hline & 1.57 & 2.26 & 1.11 & 3.69 & \\
\hline & 3.67 & 4.97 & 0.9 & & \\
\hline & 1.47 & 1.69 & 0.98 & & \\
\hline & 1.59 & 0.76 & 1.73 & & \\
\hline & 1.52 & 2.53 & 9.18 & & \\
\hline & 4.18 & 2.44 & 1.74 & & \\
\hline & 1.15 & 0.81 & 1.72 & & \\
\hline & 5.92 & 0.86 & 1.89 & & \\
\hline & 1.88 & 0.86 & 0.76 & & \\
\hline & 0.92 & 1.19 & 2.25 & & \\
\hline & 0.73 & 1.2 & 2.29 & & \\
\hline & 3.51 & 1.25 & 3.39 & & \\
\hline & 1.78 & 0.47 & & & \\
\hline & 1.2 & 0.67 & & & \\
\hline & 1.21 & 1.87 & & & \\
\hline & 2.78 & 0.69 & & & \\
\hline Average & 2.62 & 1.69 & 2.43 & 4.13 & 3.03 \\
\hline
\end{tabular}

Table 10 Follow-up headway of roundabout 1 for leg 1 and leg 2

\begin{tabular}{|c|c|c|c|c|c|c|c|c|c|c|}
\hline \multirow[t]{3}{*}{ Follower } & \multicolumn{5}{|c|}{ Leg 1} & \multicolumn{5}{|c|}{ Leg 2} \\
\hline & \multicolumn{5}{|c|}{ Leader (follow-up headway) } & \multicolumn{5}{|c|}{ Leader (follow-up headway) } \\
\hline & Car & $\mathrm{TW}$ & Auto & Bus & Truck & Car & $\mathrm{TW}$ & Auto & Bus & Truck \\
\hline Car & 2.62 & 1.69 & 2.43 & 4.13 & 3.03 & 2.01 & 2.86 & 2.10 & 2.08 & 3.43 \\
\hline TW & 2.27 & 2.99 & 2.99 & 2.37 & 3.15 & 2.12 & 2.60 & 2.25 & 2.61 & 3.60 \\
\hline Auto & 2.80 & 2.87 & 3.19 & 2.41 & 3.02 & 2.26 & 2.68 & 2.12 & 3.05 & 4.12 \\
\hline Bus & 3.68 & 3.09 & 3.33 & 3.24 & 4.84 & 3.68 & 3.09 & 3.33 & 3.24 & 4.84 \\
\hline Truck & 2.98 & 2.77 & 2.14 & 2.79 & 2.81 & 2.98 & 2.77 & 2.14 & 2.79 & 2.81 \\
\hline
\end{tabular}

\subsection{The Indian Roads Congress Method (IRC 65-1976)}

Capacity values estimated for all the legs for roundabouts 1 and 2 using IRC method (India) are given in Tables 16 and 17.

\subsection{German method}

Capacity values estimated for all the legs for roundabouts 1 and 2 using German method are given in Tables 18 and 19.

\subsection{Entry flow versus circulating flow curves}

To find the accuracy of VISSIM in reproducing the real world data, comparison between VISSIM and field values is done using entry flows and circulating flows at both the roundabouts. Curves are drawn for entry flows versus circulating flows for both field and VISSIM data. Decrease in the entry flow with the increase in circulating flow can be observed in all the curves. From the plots, it is evident that both VISSIM and field data curves are nearly matching. Figure 10a, b represents the relation between circulating 
Table 11 Follow-up headway of roundabout 1 for leg 3 and leg 4

\begin{tabular}{|c|c|c|c|c|c|c|c|c|c|c|}
\hline \multirow[t]{3}{*}{ Follower } & \multicolumn{5}{|c|}{ Leg 3} & \multicolumn{5}{|c|}{ Leg 4} \\
\hline & \multicolumn{5}{|c|}{ Leader (follow-up headway) } & \multicolumn{5}{|c|}{ Leader (follow-up headway) } \\
\hline & Car & TW & Auto & Bus & Truck & Car & TW & Auto & Bus & Truck \\
\hline Car & 2.11 & 2.80 & 2.36 & 3.45 & 4.54 & 2.24 & 2.45 & 2.30 & 3.22 & 3.67 \\
\hline TW & 2.31 & 2.64 & 2.49 & 4.56 & 2.71 & 2.23 & 2.74 & 2.58 & 3.18 & 3.15 \\
\hline Auto & 2.22 & 2.47 & 2.65 & 3.94 & 3.52 & 2.43 & 2.67 & 2.65 & 3.13 & 3.55 \\
\hline Bus & 3.68 & 3.09 & 3.33 & 3.24 & 4.84 & 3.68 & 3.09 & 3.33 & 3.24 & 4.84 \\
\hline Truck & 2.98 & 2.77 & 2.14 & 2.79 & 2.81 & 2.98 & 2.77 & 2.14 & 2.79 & 2.81 \\
\hline
\end{tabular}

Table 12 Capacity estimation using HCM 2010 method for roundabout 1

\begin{tabular}{lcccccc}
\hline Description & Circulating flow $(\mathrm{veh} / \mathrm{h})$ & $t_{\mathrm{c}}(\mathrm{s})$ & $t_{\mathrm{f}}(\mathrm{s})$ & $A$ & $B$ & Capacity $(\mathrm{veh} / \mathrm{h})$ \\
\hline Leg 1 (NB) & 1,144 & 4.10 & 2.56 & $1,403.83$ & 0.000783 & 573 \\
Leg 2 (EB) & 764 & 4.06 & 2.34 & $1,535.281$ & 0.000802 & 832 \\
Leg 3 (SB) & 1,096 & 4.28 & 2.47 & $1,459.884$ & 0.000846 & 577 \\
Leg 4 (WB) & 1,240 & 4.15 & 2.46 & $1,464.365$ & 0.00081 & 536 \\
\hline
\end{tabular}

Table 13 Capacity estimation using HCM 2010 method for roundabout 2

\begin{tabular}{lclllll}
\hline Description & Circulating flow (veh/h) & $t_{\mathrm{c}}(\mathrm{s})$ & $t_{\mathrm{f}}(\mathrm{s})$ & $A$ & $B$ & Capacity (veh/h) \\
\hline Leg 1 (NB) & 1,276 & 3.97 & 2.82 & $1,276.339$ & 0.000711 & 515 \\
Leg 2 (EB) & 880 & 4.31 & 2.13 & $1,688.06$ & 0.0009 & 764 \\
Leg 3 (SB) & 948 & 3.90 & 2.49 & $1,444.265$ & 0.000738 & 717 \\
Leg4 (WB) & 1,128 & 4.06 & 2.48 & $1,450.48$ & 0.000783 & 599 \\
\hline
\end{tabular}

flow and entry flow for leg 1 of roundabout 1 and 2 , respectively.

\subsection{Flow versus density curves}

A new method has been proposed to estimate entry capacity of each leg of the roundabout. Speeds and flows at entry of the roundabout depend on entry angle, width of the entry, composition of the vehicles, circulating flow, and flow rate. A 50-m section near the entry of the roundabout was considered for determining flow and speeds of the entering vehicles. Density values are estimated using fundamental relationships, and curves are drawn between flow and density to obtain field capacity values. Similar approach was used to estimate the capacity values using VISSIM. The flow versus density curves of leg 1 of roundabout 1 and roundabout 2 for both simulated and observed data are shown in Figs. 11 and 12. Similar curves are drawn for all the legs of both roundabouts to find capacities of each leg separately. $R^{2}$ value is found to be reasonable from both the scenarios and suitable for estimating capacity of the each leg of the roundabouts. The capacity values estimated from the field data were used for comparison.

\section{Conclusions}

The conclusions based on the comparative analysis for each roundabout by all the listed methods are presented here:

(1) TRRL (UK) regression method overestimates the capacity values when compared to the field values. This model considers detailed characterization of the roundabout geometry, while the circulating flow $\left(Q_{\mathrm{c}}\right)$ and driver characteristics are neglected.

(2) IRC method belongs to a similar category but it gives the capacity of the weaving section. This method also overestimates the capacity value.

(3) The HCM and German models consider capacity as a function of the roundabout configuration in terms of the number of lanes at entry and in circle. It also depends on driver behavior represented using critical gap $t_{\mathrm{c}}$ and follow-up time $t_{\mathrm{f}}$. Further, this method underestimates the capacity values when compared to empirical capacity values. Even though German Model considers similar parameters as in HCM model, because of the factor $n_{\mathrm{e}}$, the capacity values obtained are close to the empirical capacity values. 


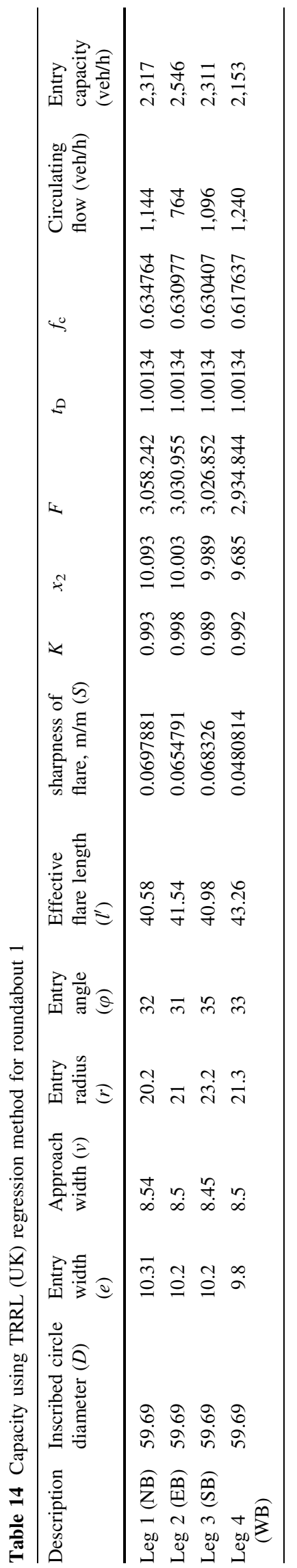

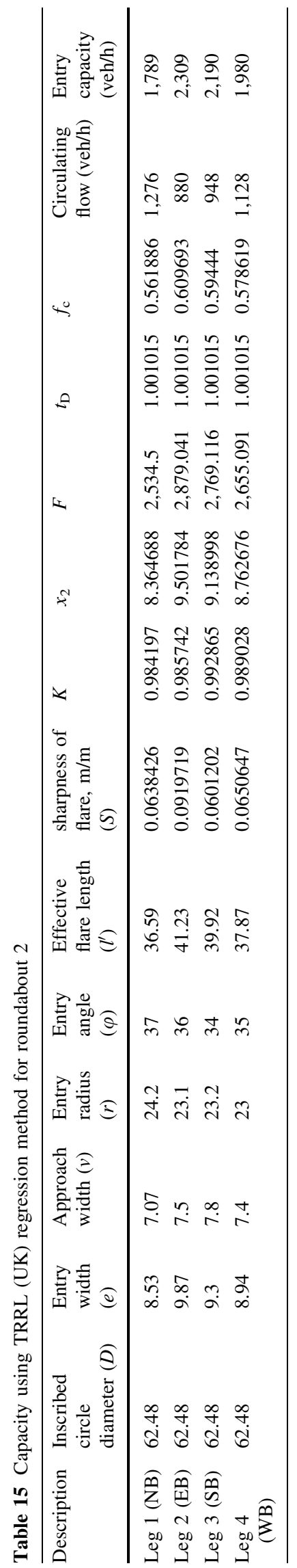


Table 16 Capacity using IRC method for roundabout 1

\begin{tabular}{llllllllllll}
\hline Weaving section & $e_{1}$ & $e_{2}$ & $e$ & $w$ & $l$ & $a$ & $b$ & $c$ & $d$ & $p$ & Capacity (veh/h) \\
\hline $\mathrm{W}_{12}$ & 10.31 & 7.06 & 8.685 & 12.185 & 38.31 & 268 & 420 & 800 & 344 & 0.665939 & 3,449 \\
$\mathrm{~W}_{23}$ & 10.2 & 7.83 & 9.015 & 12.515 & 39.32 & 296 & 900 & 568 & 196 & 0.74898 & 3,431 \\
$\mathrm{~W}_{34}$ & 10.2 & 7.11 & 8.655 & 12.155 & 41 & 188 & 768 & 624 & 472 & 0.678363 & 3,478 \\
$\mathrm{~W}_{41}$ & 9.8 & 7.65 & 8.725 & 12.225 & 37.98 & 268 & 732 & 828 & 412 & 0.696429 & 3,407 \\
\hline
\end{tabular}

Table 17 Capacity using IRC method for roundabout 2

\begin{tabular}{llllllllllll}
\hline Weaving section & $e_{1}$ & $e_{2}$ & $e$ & $w$ & $l$ & $a$ & $b$ & $c$ & $d$ & $p$ & Capacity (veh/h) \\
\hline$W_{12}$ & 8.53 & 7.38 & 7.955 & 11.455 & 40.23 & 224 & 596 & 992 & 284 & 0.757634 & 3,162 \\
$W_{23}$ & 9.87 & 8.23 & 9.05 & 12.55 & 39.34 & 316 & 796 & 728 & 152 & 0.76506 & 3,416 \\
$W_{34}$ & 9.3 & 8.12 & 8.71 & 12.21 & 38.19 & 208 & 848 & 668 & 280 & 0.756487 & 3,319 \\
$W_{41}$ & 8.94 & 8.28 & 8.61 & 12.11 & 39.38 & 356 & 780 & 632 & 496 & 0.623675 & 3,515 \\
\hline
\end{tabular}

Table 18 Capacity using German method for roundabout 1

\begin{tabular}{lcllr}
\hline Description & Circulating flow $(\mathrm{veh} / \mathrm{h})$ & $T_{\mathrm{c}}$ & $T_{\mathrm{f}}$ & Capacity $(\mathrm{veh} / \mathrm{h})$ \\
\hline Leg 1 (NB) & 1,144 & 4.10 & 2.56 & 803 \\
Leg 2 (EB) & 764 & 4.06 & 2.34 & 1,165 \\
Leg 3 (SB) & 1,096 & 4.28 & 2.47 & 808 \\
Leg 4 (WB) & 1,240 & 4.15 & 2.46 & 751 \\
\hline
\end{tabular}

Table 19 Capacity using German method for roundabout 2

\begin{tabular}{lcllr}
\hline Description & Circulating flow $(\mathrm{veh} / \mathrm{h})$ & $T_{\mathrm{c}}$ & $T_{\mathrm{f}}$ & Capacity $(\mathrm{veh} / \mathrm{h})$ \\
\hline Leg 1 (NB) & 1,276 & 3.97 & 2.82 & 722 \\
Leg 2 (EB) & 880 & 4.31 & 2.13 & 1,071 \\
Leg 3 (SB) & 948 & 3.90 & 2.49 & 1,004 \\
Leg 4 (WB) & 1,128 & 4.06 & 2.48 & 840 \\
\hline
\end{tabular}

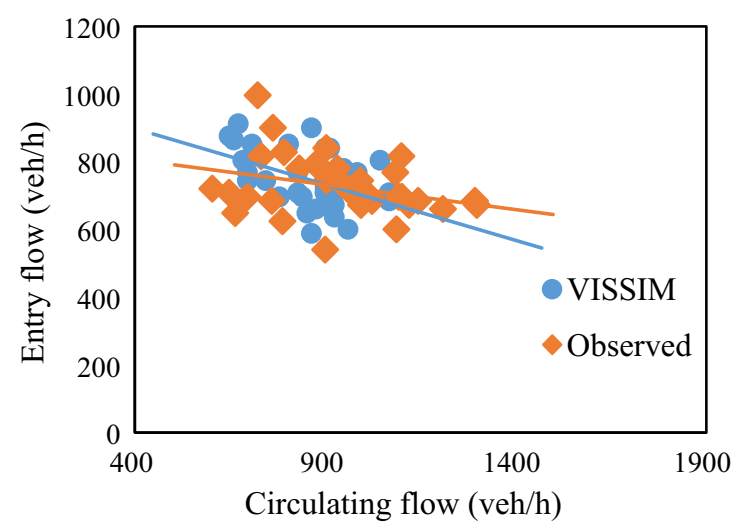

(a)

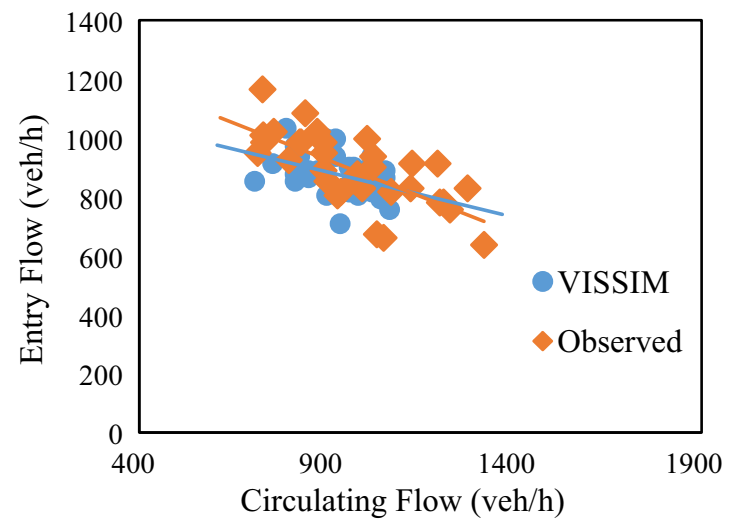

(b)

Fig. 10 Entry versus circulating flow for a roundabout 1, leg 1 and $\mathbf{b}$ roundabout 2, leg 2 


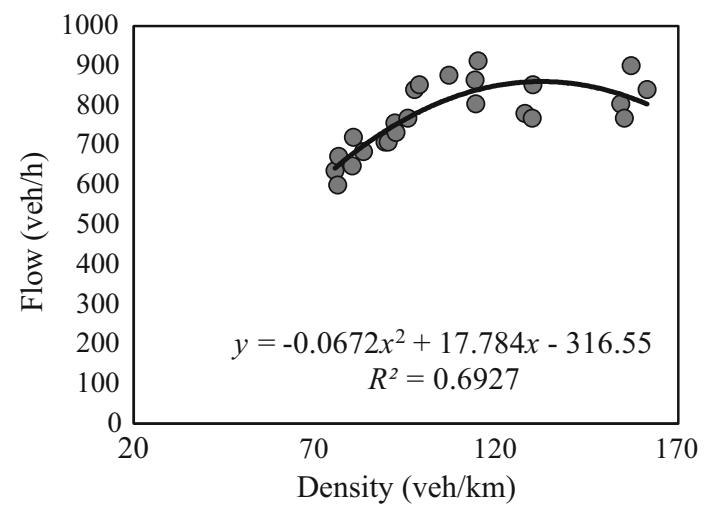

(a)

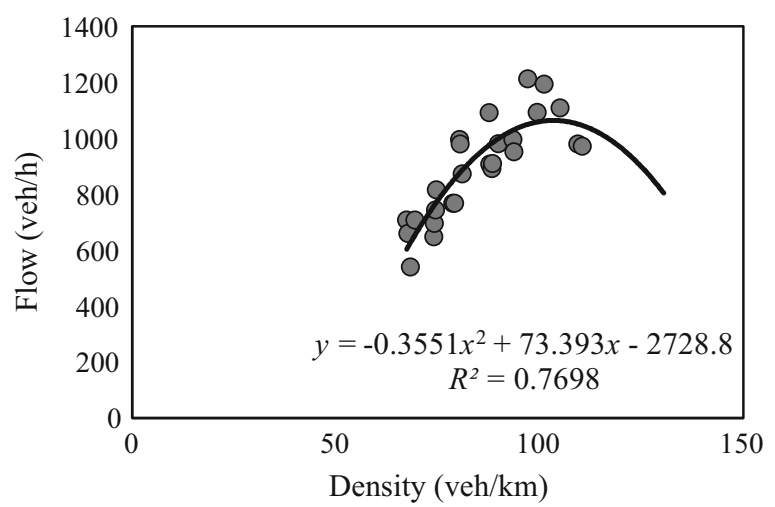

(b)

Fig. $11 q$ versus $k$ curve of a roundabout 1 , leg 1, VISSIM data, b $q$ versus $k$ curve of roundabout 1 , leg 1 , observed data

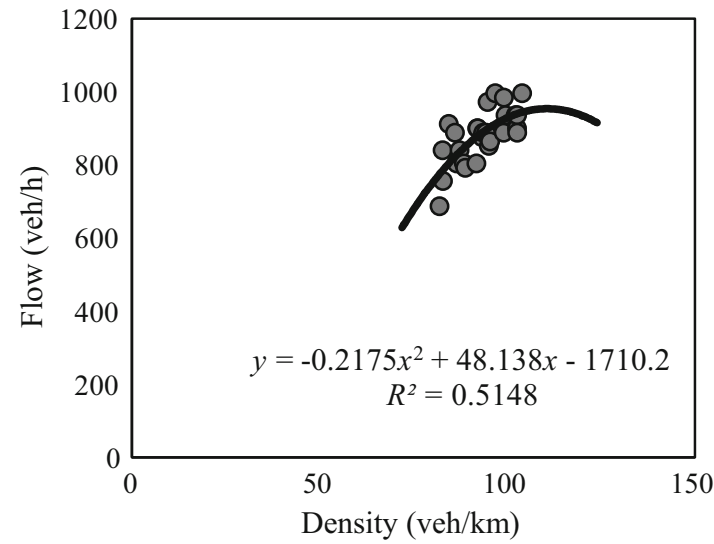

(a)

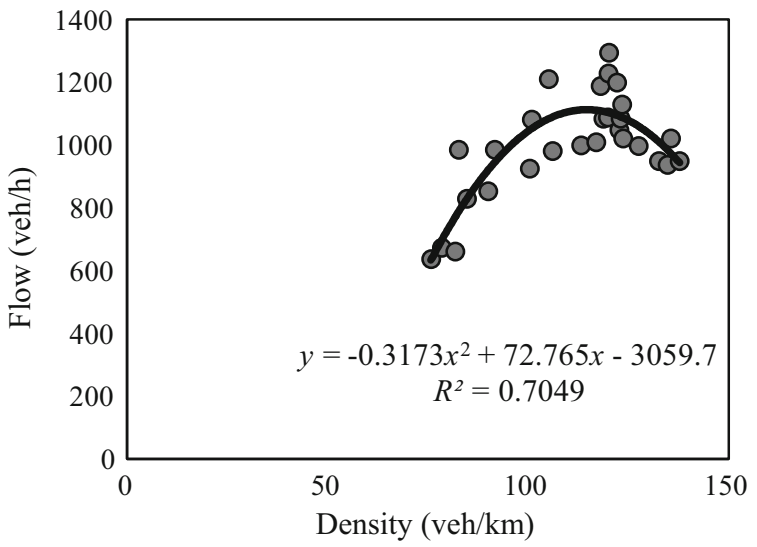

(b)

Fig. $12 q$ versus $k$ curve of a roundabout 2, leg 1, VISSIM data b roundabout 2, leg 1, observed data

Table 20 Capacity comparison for roundabout 1 and roundabout 2

\begin{tabular}{|c|c|c|c|c|c|c|c|c|}
\hline \multirow[t]{2}{*}{ Description } & \multicolumn{4}{|c|}{ Roundabout 1} & \multicolumn{4}{|c|}{ Roundabout 2} \\
\hline & Leg 1 & Leg 2 & Leg 3 & Leg 4 & Leg 1 & Leg 2 & Leg 3 & Leg 4 \\
\hline HCM method & 573 & 832 & 577 & 536 & 515 & 764 & 717 & 599 \\
\hline TRRL method & 2,317 & 2,546 & 2,311 & 2,153 & 1,789 & 2,309 & 2,190 & 1,980 \\
\hline IRC method & 3,449 & 3,431 & 3,478 & 3,407 & 3,162 & 3,416 & 3,319 & 3,515 \\
\hline German method & 803 & 1,165 & 808 & 751 & 722 & 1,071 & 1,004 & 840 \\
\hline VISSIM model & 860 & 835 & 910 & 800 & 945 & 850 & 1,000 & 960 \\
\hline Observed & 1,060 & 938 & 976 & 932 & 1,112 & 998 & 1,135 & 1,138 \\
\hline
\end{tabular}

(4) The capacity values obtained from VISSIM are almost matching with the field capacity values. This is because VISSIM incorporates the geometry of the roundabout which is coded using links and connectors with greater precision, and the driver gap acceptance behavior which is controlled by the priority rules. Moreover, with better calibration, the field conditions represented in the VISSIM model help in estimating the actual capacity of the roundabout.
It is this evident that German model works well compared to all other steady-state capacity equations. Further, VISSIM has emerged as a better candidate for estimating capacity values for heterogeneous traffic conditions. Capacity values obtained from various methods are shown in Table 20. The comparative evaluation of the capacity values from various methods is depicted in Figs. 13 and 14. 


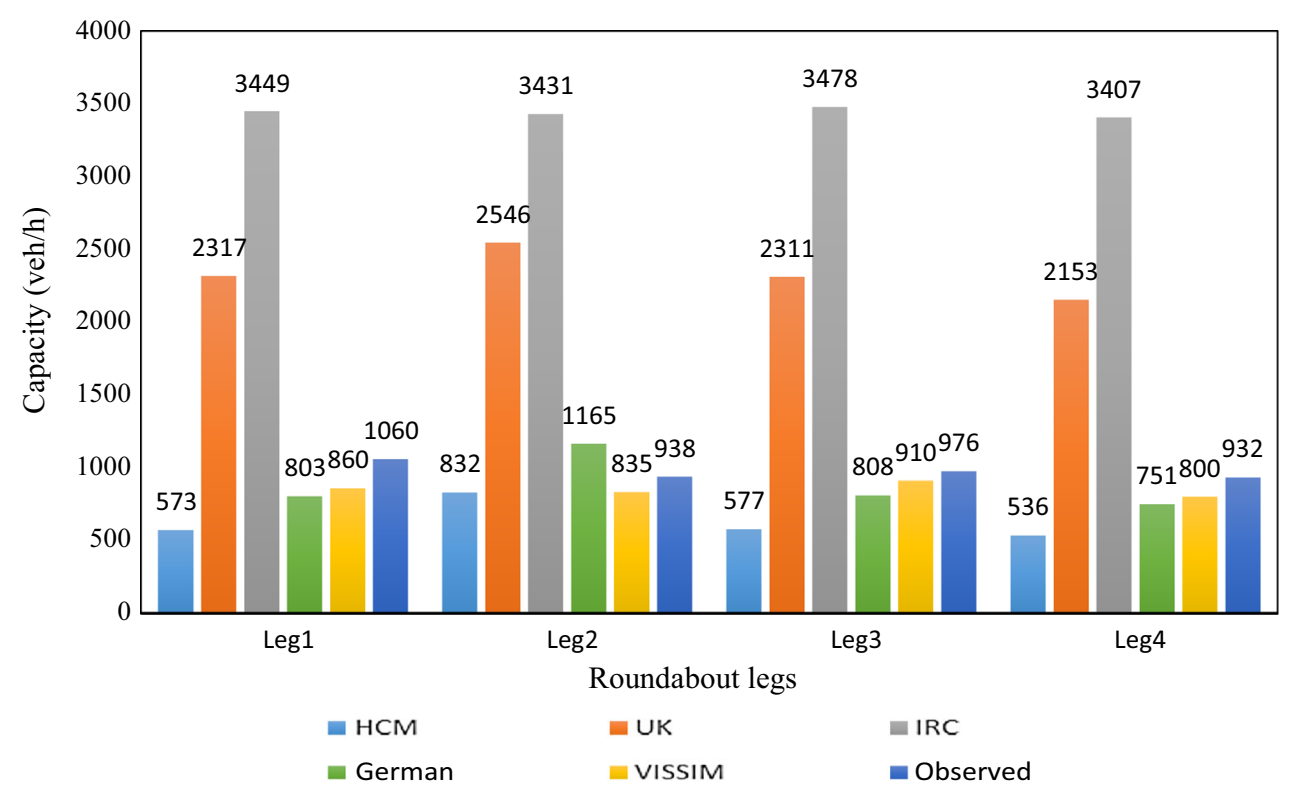

Fig. 13 Comparison of capacity by various methods for roundabout 1

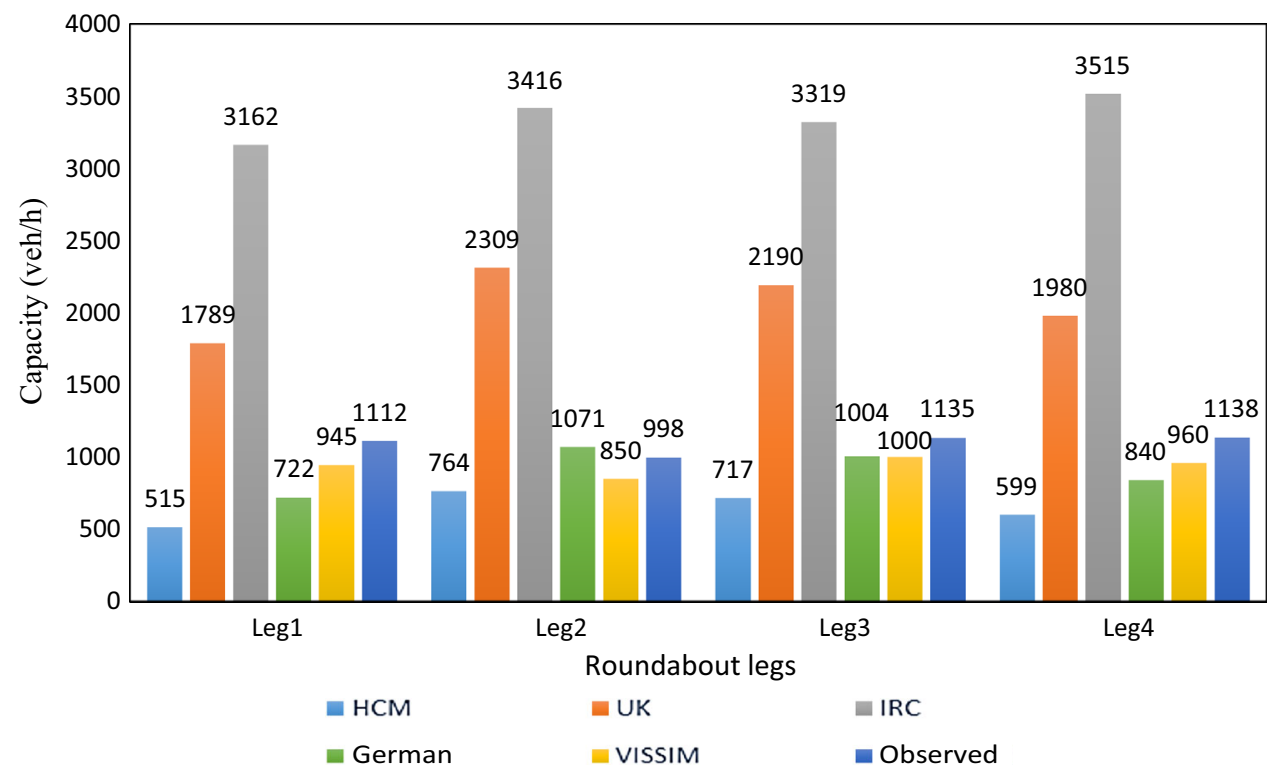

Fig. 14 Comparison of capacity by various models for roundabout 2

\subsection{Future scope}

The methodology of calibration is important for VISSIM simulation as it will influence the results significantly. In the present study, a heuristic method is used. This is a trial and error procedure in which the parameters are altered in various simulation runs and the parameters with least MAPE values are considered as calibrated values. The error obtained in this study may be a local error and there might be other set of parameters with less error. Further studies are needed with methods of calibration which work on minimizing the error through genetic algorithm approach and VISSIM's Component Object Model (COM) interface. This may possibly lead to better simulation results, which represents the traffic realistically.

Open Access This article is distributed under the terms of the Creative Commons Attribution 4.0 International License (http:// creativecommons.org/licenses/by/4.0/), which permits unrestricted use, distribution, and reproduction in any medium, provided you give appropriate credit to the original author(s) and the source, provide a 
Table 21 Parameter optimization results

\begin{tabular}{lll}
\hline S. no. & $\begin{array}{l}\text { VISSIM parameter set } \\
\left(a x, b x \_ \text {add, } b x \_ \text {mult }\right)\end{array}$ & MAPE $(\%$ ge $)$ \\
\hline 1 & 1.710 & 20.00 \\
& 3.964 & \\
& 4.141 & \\
& 1.2928 & 10.14 \\
2 & 4.2479 & \\
& 3.8297 & 13.05 \\
& 2.2831 & \\
& 4.0898 & \\
& 1.3773 &
\end{tabular}

link to the Creative Commons license, and indicate if changes were made.

\section{Appendix}

Parameter optimization procedure through GA.

This module was developed to check whether the parameter optimization yields better results. The procedure suggested by Tettamanti et al. (2015) was adopted. Some of the parameters used in the simulation with MATLAB interface with VISSIM are presented here. MAPE values are showing mixed response to this procedure, which needs further investigation.

Population $=50$.

Total parameters considered $=3$ (Average standstill distance ( $a x)$, additive part of safety distance ( $b x \_$add), multiplicative part of safety distance, $b x \_$mult).

No. of generations $=10$.

Target of optimization $=$ Speed.

The results obtained with optimized parameters are given in Table 21.

\section{References}

1. Ariniello A, Przybyl B (2010) Roundabouts and sustainable design. Green Str Highw 2010:82-93

2. Mauro R, Cattani M (2004) Model to evaluate potential accident rate at roundabouts. J Transp Eng 130(5):602-609

3. Mauro R (2010) Calculation of roundabouts, capacity, waiting phenomena and reliability. Springer, New York

4. IRC: 65-1976 (1976) Recommended practice for traffic rotaries. The Indian Roads Congress, New Delhi
5. Dahl J, Lee C (2012) Empirical estimation of capacity for roundabouts using adjusted gap-acceptance parameters for trucks. Transp Res Rec 2312:34-45

6. Yap YH, Gibson HM, Waterson BJ (2013) An international review of roundabout capacity modelling. Transp Rev 33(5): 593-616

7. Mauro R, Branco F (2010) Comparative analysis of compact multilane roundabouts and turbo-roundabouts. J Transp Eng 136(4):316-322

8. Robinson BW, Rodegerdts L (2000) Capacity and performance of roundabouts: a summary of recommendations in the FHWA roundabout guide, transportation research circular E-C018. In: 4th international symposium on highway capacity proceedings

9. Polus A, Vlahos E (2005) Evaluation of roundabouts versus signalized and unsignalized intersections in delaware, report. Delaware Center for Transportation

10. Liang Q, Liu P, Wang H, Yu H (2012) Can highway capacity manual model be used to estimate the capacity of modern roundabouts in China: a case study in Nanjing CICTP 2012: multimodal transportation systems-convenient, safe, cost-effective, efficient. ASCE

11. Chandra S, Rastogi R (2012) Mixed traffic flow analysis on roundabouts. J Indian Roads Congress, 73(1), Indian Roads Congress, New Delhi, pp 69-77

12. Trueblood M, Dale J (2004) Simulating roundabouts with VISSIM. Kansas City, 2nd Urban Street Symposium Missouri, 2004 (www.kutc.ku.edu)

13. Al-Ghandour M (2013) Experimental analysis in VISSIM of single-lane roundabout slip lane under varying bus traffic percentages, urban public transportation systems, pp 113-123

14. Li Z, DeAmico M, Chitturi MV, Bill AR, Noyce DA (2013) Calibration of VISSIM roundabout model: a critical gap and followup headway approach. In: Proceedings TRB 92nd annual meeting, Washington, D.C., January, 2013

15. Gavulova A, Drliciak M (2011) Microsimulation using for capacity analysis of roundabouts in real conditions. In: Proceedings of the 11th international conference, reliability and statistics in transportation and communication

16. Hallmark SL, Fitzsimmons EJ, Isebrands HN (2010) Evaluating the traffic flow impacts of roundabouts in signalized corridors. Annual Meeting of the Transportation Research Board

17. Brilon W, Wu N, Bondzio L (1997) Unsignalized intersections in Germany - a state of the art 1997. In: Proceedings of the third international symposium on intersections without traffic signals, Portland, Oregon, pp 61-70

18. Dixon M, Abdel-Rahim A, Kyte M, Rust P, Cooley H, Rodegerdts L (2007) Field evaluation of roundabout turning movement estimation procedures. J Transp Eng 133(2):138-146

19. Yousif S, Razouki SS (2007) Validation of a mathematical model to estimate turning movements as roundabouts using field data, Universities Transport Studies Group 39th Annual Conference, University of Leeds, 3-5 January 2007 (unpublished)

20. Fitzpatrick C, Abrams D, Tang Y, Knodler M (2013) A spatial and temporal analysis of driver gap acceptance behavior at modern roundabouts. J Transp Res Board 2388:14-20

21. Tettamanti T, Csikós A, Varga I and Eleőd A (2015) Iterative calibration of VISSIM simulator based on genetic algorithm. Acta Tech Jaurinensis 8(2):145-152 